\title{
Watch the colors: or about qualitative thinking in chemistry
}

\section{Wojciech Grochala ${ }^{1}$}

Published online: 4 June 2020

(C) The Author(s) 2020

\begin{abstract}
The importance of watching and understanding color of chemical compounds and linking it to diverse physical and chemical properties is illustrated here using transition metal oxides at the highest achievable oxidation state of a metal. Analyses are based on qualitative thinking supported by Molecular Orbital theory in its simplest implementation.
\end{abstract}

\section{Graphic abstract}
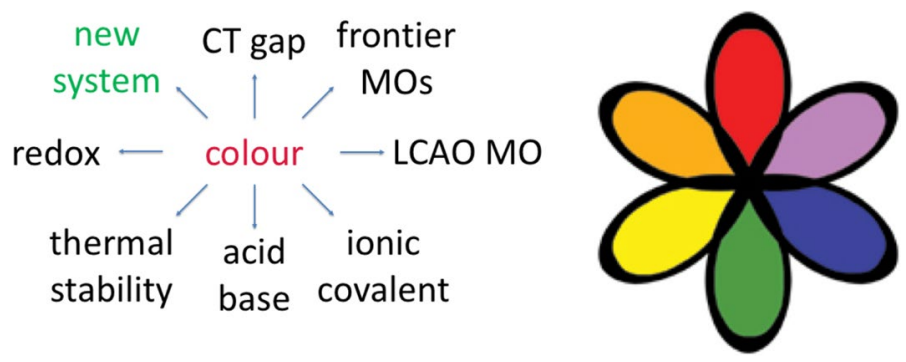

Keywords Coordination compounds $\cdot$ Ligand field theory $\cdot$ Descriptive chemistry $\cdot$ MO theory $\cdot$ Periodicity $\cdot$ Physical properties

\section{Introduction}

Teaching of chemistry inevitably involves experiments. From the earliest steps, a school pupil and later a chemistry student is encouraged to mix substances, and observe-be it the evolving gas, the sedimentation of a solid, the more noble metal covering the surface of a less noble one ("electromotive" series), the separation of phases, or the change of color inside a test tube. All these phenomena are dramatic, hard to be forgotten, and once they are understood, the visual (and sometimes also sonic) experience helps one to remember the outcome of reaction and the science beyond it. However, in most cases the observation of color changes are either linked to some sort of acid-base indicator, or they are linked to recognition of a color specific to a given product of reaction; $\mathrm{Mn}(\mathrm{IV}) \mathrm{O}_{2}$ is brown,

Wojciech Grochala

w.grochala@cent.uw.edu.pl

1 Center of New Technologies, University of Warsaw, Zwirki i Wigury 93, 02089 Warsaw, Poland 
$\mathrm{Mn}(\mathrm{VII}) \mathrm{O}_{4}^{-}$is violet, $\mathrm{Mn}(\mathrm{II}) \mathrm{Cl}_{2}$ is pink, and $\mathrm{Mn}(\mathrm{VI}) \mathrm{O}_{4}^{2-}$ is green. Once these characteristic colors are remembered by a student, the fate of yet another reaction involving some $\mathrm{Mn}$ bearing substrate may be identified faster and with greater confidence. And yet, there is so much more science beyond each of these colors, which utility in chemical education can be greatly enhanced.

Another important aspect of chemistry teaching at university level is related to division of teaching to specific courses, those on inorganic, organic, metalorganic, physical, analytical, and theoretical chemistry, often also electrochemistry, biochemistry, etc., as well as on instrumental methods, in particular spectroscopic ones. However, when the education seems to be complete, and the young adept of chemical sciences seems to be equipped with the entire suite of diverse tools for conducting research, or teaching, he or she often thinks about those different subdisciplines as separate, or even unlinked fields. While the need for systematic introduction of a language specific to each discipline may easily be understood, it is highly unsatisfactory that education of young chemists does not terminate with some sort of holistic course where are the links would be made clear, and a chemistry graduate would have a chance to become of a more of a "renaissance person" in his field.

It is very typical to treat theoretical chemistry as a separate world from experimental one; this is emphasized by the need for theoreticians to calculate structures and properties of chemical compounds, and to achieve quantitative agreement with experimental data. Rarely, a theoretician would be asked by his experimental colleague to design or predict a system that might be worth looking at in experiment. While some theoreticians do just that, they usually fail to communicate their discoveries to experimentalists, either due to hermetic language of their subdiscipline (notice, as early as in XIX century Michael Faraday could not understand the mathematical form of his laws which utilized higher mathematics, which was at that time introduced by Newton and Leibnitz), or the fact that different theoretical methods usually deliver different numbers describing a given property (hence, experimentalists' mistrust is natural), or simply because prolific theoreticians may rather rapidly come up with a multitude of new hypothetical systems, while experimental verification may be troublesome and takes a lot of time and resources. This creates a painful rupture between most advanced modern theoretical calculations and plain experiment.

Chemistry is an art of making stuff, and no other specialists (physicists, biologists, etc.) may ever substitute us in this major mission of ours. The chemical craftsmanship requires frequent dealing with many different but also many related substances; in the course of events, a chemist naturally develops a sort of feeling, or intuition, which permits to have expectations regarding the fate of a chemical reaction (some are not worth trying, some are more promising than others, etc.), or the properties of the desired product. Comparative analysis greatly facilitates this intuition, and chemist usually makes links between the behavior of a new system prepared and those of many others; an inorganic chemist performs gedankenexperiments by substituting one element for the other either moving to the left or right within a given Period of the Table, or up and down within a given Group. While the great mission of chemistry to deliver "set of physicochemical properties by design" is definitely in its early stages (as exemplified by Materials Genome initiative, https://www.nist.gov/mgi), a chemist is well equipped with the knowledge of what modifications of properties are brought by different functional groups, for example. While a modern theoretical chemist is capable of credibly predicting anything an experimentalist needs, yet he or she usually lacks this sort of intuition which comes mostly from experimental observations. This feature renders theoretical chemists similar to physicists, for which every chemical composition constitutes a totally different system for research, hardly related to any other they already studied (unless such similarity will be proved 
at some point). Certainly, this remark is not meant to hurt anyone's feelings and it is certainly untrue in many cases, but it is a feature of every generalization. Indeed, there are exceptional theoretical chemists who are able to predict major features of the outcome of their calculation before they even do it. As noticed by my great teacher, Hoffmann, in his influential 1998 paper "Qualitative thinking in the age of modern computational chemistry-or what Lionel Salem knows" (Hoffmann 1998):

The calculations, whatever formalism is followed, are elaborate. What happens next is an imaginary dialogue between the experimentalist and the theorist. The experimentalist asks: 'What is the bond angle of water?' You, the theorist, plug it into the best programs available and you get it right to three significant figures. Everyone is happy. Then the experimentalist asks the same question for $\mathrm{TeH}_{2}$. You say 'Wait a minute, I have to calculate it...' and you get that right: and you get right $\mathrm{Li}_{2} \mathrm{O}$ and $\mathrm{F}_{2} \mathrm{O}$ as well. But if that's all you do, no matter how well you do it, the experimentalist will grow increasingly unhappy. Because you haven't provided him/her with a simple, portable explanation, one based on electronegativity. or relative energies of $\mathrm{s}$ and $\mathrm{p}$ orbitals, or donor or acceptor character or whatever set of factors he or she feels comfortable with. The experimentalist will think 'This theorist is only good at simulating experiments'; or, less charitably, 'The computer understands, this theorist doesn't'. Which is not too bad. Sometimes that predictability is needed, sometimes it's quicker, or as Fritz Schaefer so aptly calls it in a paper, 'odorless'. Sometimes it even gets the facts right before experiment: the story of the ground and excited states of $\mathrm{Si}_{2} \mathrm{H}_{2}$ is an exemplary case. In many interesting areas of chemistry we are approaching predictability, but... I would claim, not understanding.

And then Hoffmann adds:

Let me digress here to give a simple pedagogic strategy which I teach for eliciting understanding. This is to alternate the computational and the 'understanding' roles. I define understanding (operationally, if faced with a really good computer program and a complex problem), as being able to predict qualitatively (this forces you to think before) the result of a calculation before that calculation is carried out. If the calculation's result differs from what your understanding gives you, well, then it's time to think again, do numerical experiments until you rationalize (that's also to 'understand') the results. Until the explanation is so clear that you could kick yourself in the butt for not having seen why. But don't stop, iterate the process, go on. Understanding will build if you follow this way of analysis.

This contribution is aimed at using of an easily observable property of color for supporting chemical education, i.e. as a pretext for building up of chemical intuition regarding many different properties of chemical matter using simple comparative analyses and the Molecular Orbital theory in its simplest form, which in turn will enable to qualitatively predict the properties of an as yet unknown chemical system. This will be followed by validation of the predictions based on most recent advanced theoretical calculations for that system, $\mathrm{FeO}_{4}$, already existing in the literature. 


\section{The series of oxides of d-block elements at their highest oxidation state}

\section{Just how pleasingly different these colors are!}

Let us take an actual look at the series of transition metal (TM) oxides at the highest oxidation state of a metal, placed by each other in the arrangement corresponding to the order of these elements within the IV Period of the Periodic Table (Fig. 1). Oxidation states here are assigned in the conventional way that all chemistry students learn, starting with 2- for oxygen (oxide dianion). $\mathrm{Sc}(\mathrm{III})_{2} \mathrm{O}_{3}$ is snow white, so is $\mathrm{Ti}(\mathrm{IV}) \mathrm{O}_{2} . \mathrm{TiO}_{2}$ is actually sold globally as a white paint (https://en.wikipedia.org/wiki/Titanium_dioxide). But $\mathrm{V}(\mathrm{V})_{2} \mathrm{O}_{5}$ is orange, and most often used as a catalyst of oxidation reactions (https://en.wikipedia. org/wiki/Vanadium(V)_oxide). Next, $\mathrm{Cr}(\mathrm{VI}) \mathrm{O}_{3}$ is blood red, and if admixed with sulphuric acid, helps to remove all impurities from laboratory glassware ("Piranha solution") (https ://en.wikipedia.org/wiki/Chromium_trioxide). All of them are solids at ambient (p, T) conditions. $\mathrm{Mn}(\mathrm{VII})_{2} \mathrm{O}_{7}$ is dark green, and it is an explosive liquid which must be handled with care; it is used on a small scale for demonstrating of a spectacular "thunderstorm in a test tube" experiment (https://www.thoughtco.com/test-tube-thunderstorm-demonstration604255). $\mathrm{Mn}_{2} \mathrm{O}_{7}$ closes this colorful series, because $\mathrm{Fe}(\mathrm{VIII}) \mathrm{O}_{4}$ has never been prepared. These colors begs for explanation. One should be also able to deduce why $\mathrm{FeO}_{4}$ has never been prepared, what conditions are required for its possible preparation in the future, and what properties this compound would have.

\section{Color comes from an electronic absorption}

In virtually every molecule or a solid, the color comes from an electronic absorption. This implies an electron transfer from some occupied orbital to an unoccupied one, an inherently quantum-mechanical process. While not all electronic absorptions are symmetryallowed, there are diverse reasons for bending the selection rules; in fact, every electronic excitation has some non-zero probability (even the spin-forbidden ones). However, due to a special set of favorable conditions, which will be outlined below, the analysis of electronic absorptions in the series discussed is very simple.

Assuming provisionally an ionic picture of bonding (as a freshmen would do for most oxides or salts in general), one is forced to consider the isoelectronic series of cations: Sc(III), Ti(IV), V(V), Cr(VI), Mn(VII) and Fe(VIII). Most students remember or with the help of the Periodic Table can establish that the number of valence electrons in a group No. $\mathrm{N}$ is equal to $\mathrm{N}$; hence, as in the considered case, cations at the $\mathrm{Nth}$

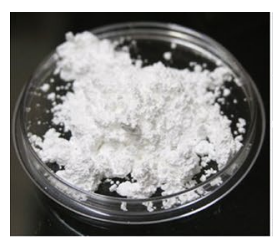

$\mathrm{Sc}_{2} \mathrm{O}_{3}$

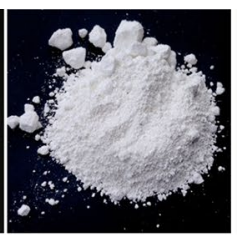

$\mathrm{TiO}_{2}$

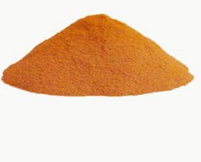

$\mathrm{V}_{2} \mathrm{O}_{5}$

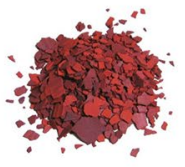

$\mathrm{CrO}_{3}$

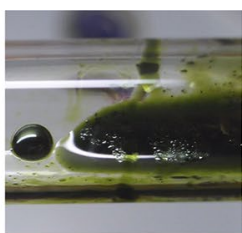

$\mathrm{Mn}_{2} \mathrm{O}_{7}$

Fig. 1 Photos of five TM oxides at the highest available oxidation state of a metal. Solid $\mathrm{Mn}_{2} \mathrm{O}_{7}$ is also dark green 
oxidation state have no valence electrons at all; in other words, their d states are empty. This means that the $\mathrm{d}-\mathrm{d}$ transitions (which usually give weak absorption anyway) cannot be responsible for the observed color. Therefore, the only possibility is to transfer electrons between nonmetal and metal; these are so called charge transfer (CT) transitions. Two of those are frequently found in inorganic and organometallic compounds: the ligand-to-metal and the metal-to-ligand CT transitions, LMCT and MLCT, respectively. However, the latter are observed only if the ligand has low-lying acceptor states (as for $\mathrm{CN}^{-}$group), and if metal has some electrons available in the $\mathrm{d}$ states. Here, $\mathrm{O}^{2-}$ anion lacks such empty (acceptor) orbitals, while metal center lacks d electrons, hence only the LMCT transition is possible. In short, electron-rich $\mathrm{O}$ center is a donor, while electron-hungry TM cation is an acceptor of electron in this transition. The energy of this excitation is its key property. So, in which of these compounds an electron jump costs most energy, and in which one the least?

Provisionally assuming that the color of the TM oxides analyzed originates from a single electronic transition, one may easily deduce which excitation requires most energy. The color of the compound corresponds to this part of the electromagnetic spectrum (Fig. 2) which is not absorbed by the compound. Therefore, light absorbed corresponds to complementary color. The easy-to-be-remembered color wheel (Fig. 2) indicates which pairs of colors are complementary to each other. Thus, $\mathrm{V}_{2} \mathrm{O}_{5}$ which is orange, absorbs mostly the blue part of the spectrum; red $\mathrm{CrO}_{3}$ absorbs green, while green $\mathrm{Mn}_{2} \mathrm{O}_{7}$ absorbs red. The trend is clear: as one moves from the left to the right along Period IV, electronic absorption of the TM oxides shifts to longer and longer wavelength, $\lambda$, hence it costs less and less energy, $\Delta \mathrm{E}_{\mathrm{CT}}$. The colorless $\mathrm{Sc}_{2} \mathrm{O}_{3}$ and $\mathrm{TiO}_{2}$ do not absorb any part of the visible spectrum, hence, to fit the trend, they should absorb light of even higher energy, i.e. somewhere in the near-UV (NUV) region.

Obviously, situation may be more complex. Compounds are known where their color comes from two or more electronic absorption bands. E.g., orange appearance may originate from a combination of yellow and red, and therefore the absorption may be somewhere in violet and green regions simultaneously. The visual analysis may be subjective, and percepted color may depend on many factors such as grain size etc. However, electronic absorption bands are usually broad, especially in extended solids, and our example of TM oxides fortunately falls into this category. Moreover, for TM compounds their strong color often originates from the lowest energy optically active excitation, the others being well separated in energy from the lowest energy one. The analysis of color unsupported by specialized equipment is a crude qualitative analysis par excellence. And yet, as we will see below, it is so useful.
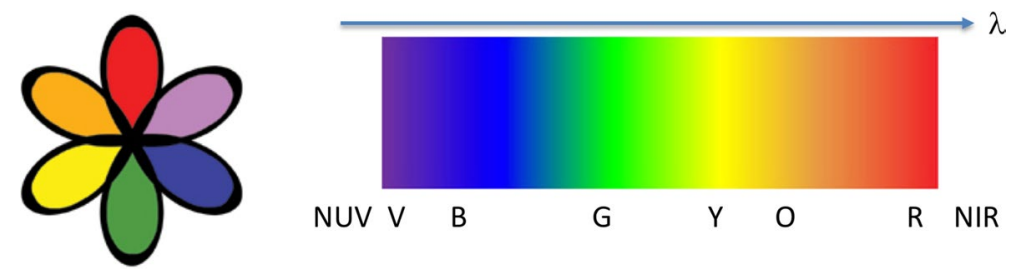

Fig. 2 Left: Color wheel-with three basic colors (RYB), and three coming from their mixtures (violet $=\mathrm{R}+\mathrm{B}$, green $=\mathrm{B}+\mathrm{Y}$, orange $=\mathrm{R}+\mathrm{Y}$ ). The complementary colors are opposite to each other in the wheel. Right: the schematic part of electromagnetic spectrum encompassing visible region and two neighbouring ones 


\section{Frontier molecular orbitals and bits and pieces of LCAO MO theory made as simple as possible}

The simplest piece of theoretical chemistry taught at the university level is probably the Molecular Orbital theory, which is then used e.g. as the ligand field theory (LFT) framework; similarities and differences between the ligand field and crystal field approaches are readily analyzed. In a solid, the orbitals form bands of a given dispersion (band width), drawn as filled or empty boxes at the basic introduction to the solid-state chemistry. Nevertheless, one may approximate an electronic structure of a semiconducting or insulating solid by just two lines; one represents top of the valence band (highest occupied crystal orbital, $\mathrm{HOCO}$ ), and another the bottom of the conduction band (the lowest unoccupied crystal orbital, $L U C O$ ). These are analogs of HOMO and LUMO for molecules, respectively.

Just like for dihydrogen molecule, one may form MOs of the said transition metal oxides using linear combination of atomic orbitals (LCAO method). A good student knows that both $\mathrm{d}$ as well as $\mathrm{s}$ and $\mathrm{p}$ valence orbitals are needed to describe the TM series. However, in the spirit of the simplified LFT we will discard here the $\mathrm{s}$ and $\mathrm{p}$ ones (they might be added at the end as a perturbation, but we will skip this late stage here). Also, we will not dwell into the actual s-p hybridization at oxide ligands, and assume that there are four lone electron pairs (usually p-rich s-p hybrids) at each $\mathrm{O}$ atom in the ionic picture. In the same ionic picture, one is forced to consider the isoelectronic series of cations: $\mathrm{Sc}(\mathrm{III}), \mathrm{Ti}(\mathrm{IV})$, $\mathrm{V}(\mathrm{V}), \mathrm{Cr}(\mathrm{VI}), \mathrm{Mn}(\mathrm{VII})$ and $\mathrm{Fe}(\mathrm{VIII})$. As already said, the considered d states are empty in the ionic picture. Although there are obviously five $d$ orbitals at each of those, and four orbitals at $\mathrm{O}^{2-}$ sites, and there is a diversity of possible shapes of the first coordination sphere of a metal, for the sake of demonstration one may simplify the picture even further by considering only one $\mathrm{d}$ orbital at a metal site, and one $\mathrm{p}$ orbital at the $\mathrm{O}$ site. In this way, the whole complexity of the systems studied is reduced to the smallest conceivable $\mathrm{H}_{2}$ molecule-like representation of frontier orbitals. In more complex picture there will be as many as $5+2 \mathrm{~N}$ orbitals for even number members of the series, and $10+4 \mathrm{~N}$ orbitals for odd members (considering only d orbitals of a metal and $\mathrm{p}$ ones of a nonmetal); some of those will be degenerate, others not, depending on many factors. Our simplified MO system has only two MOs, the occupied one (HOCO) and the unoccupied one (LUCO). In the perfect ionic picture $\mathrm{HOCO}$ is $100 \%$ coming from ligand (nonmetal) orbital(s), while LUCO is $100 \%$ centered on a TM, and they do not mix. This is an ideal starting point for making perturbations and thinking qualitatively.

\section{Fundamental band gap}

The optical band gap is usually smaller than the fundamental band gap due to the fact that the excited electron and the hole left in the valence band attract each other coulombically. Sometimes the situation is even more complex, due to peculiarities of the band structure (direct vs. indirect band gap; forbidden absorption at certain k-points of the Brillouin zone, symmetry rules, etc.). Still, in the discussed isoelectronic series the coulombic effects should be comparable for each member of the series; hence, the trend seen in the energies of optical absorption should reflect the trend for the fundamental band gap (i.e. the HOCO/ LUCO gap) (Fig. 3). Notice that the energies of HOCO at nonmetal are in the first approximation identical for the entire series; it is true, in the gas phase $\mathrm{O}^{2-}$ spontaneously loses 


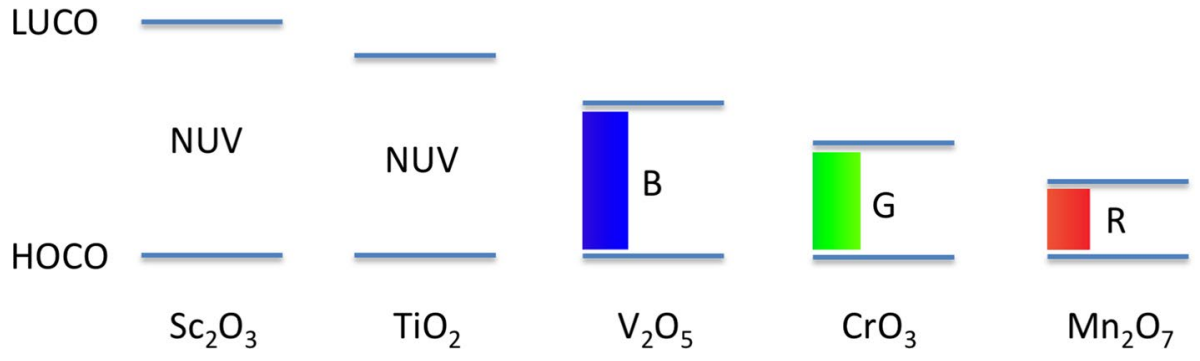

Fig. 3 The schematic drawing of the fundamental band gap of five related solids containing isoelectronic cations, solids as approximated by optical gap

an electron, but when surrounded by cations in the solid state it forms occupied electronic bands; the associated work function from typical oxides is of the order of 5-5.5 eV. Hence, we will draw its energy as a constant in the first round of perturbation (Fig. 3).

Since the acceptor function of the considered compounds is made predominantly of $\mathrm{d}$ orbitals of a metal, one may suppose that these orbitals have more and more negative energy, as one moves from the left to the right in the Period IV. But should they? Since the $\mathrm{Sc}(\mathrm{III}), \mathrm{Ti}(\mathrm{IV}), \mathrm{V}(\mathrm{V}), \mathrm{Cr}(\mathrm{VI}), \mathrm{Mn}(\mathrm{VII})$ and $\mathrm{Fe}(\mathrm{VIII})$ species are isoelectronic, and they contain progressively more protons in the TM nucleus, at the same number of electrons, the binding energies for the d orbitals should grow indeed (Fig. 4).

The indicated oxidation states, as the community understands them, are a convenient fiction. The actual charges on the atoms are much smaller. But the oxidation states indicate a direction which is understandable-if electrons were to occupy the d orbitals, they would encounter a smaller positive charge for $\mathrm{Cr}$ (VI) than $\mathrm{Fe}$ (VIII). Another model which allows one to understand this (and which applies just as much to the series $\mathrm{Li}, \mathrm{Be}, \mathrm{B}, \mathrm{C}, \mathrm{N}, \mathrm{O}, \mathrm{F}$ ) is that all of the metal centers are shielded by the partially shared electrons coming from the surrounding oxide anions. This reduces the real charge an outer electron feels, but the shielding is increasingly ineffective (and thus the effective charge that the outer orbitals/ electrons feel more positive) as one moves to a higher oxidation state metal.

In fact, the trend of BEs in the gas phase is similar but much more steep; note, electron affinity $\left(\mathrm{E}_{\mathrm{A}}\right)$ of naked $\mathrm{Mn}(\mathrm{VII})$ cation is about $11,500 \mathrm{~kJ} \mathrm{~mol}^{-1}$ (sic!) but only ca. $2390 \mathrm{~kJ} \mathrm{~mol}^{-1}$ for $\mathrm{Sc}(\mathrm{III})$. This obviously comes from the fact that the naked cations in the

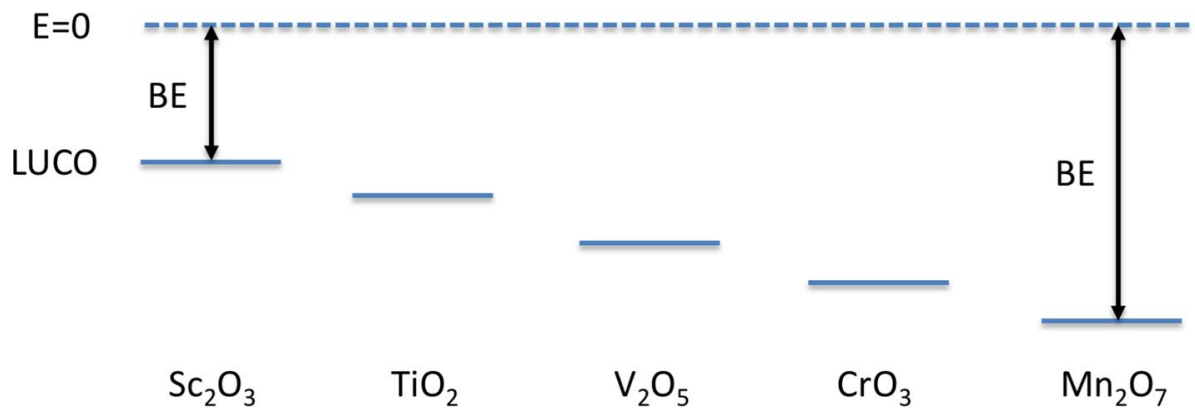

Fig. 4 The trend of binding energies (BEs) for acceptor levels of the isoelectronic series considered. Energy of an electron in vacuum is set to 0 
gas phase exert huge Coulombic attraction on electrons. Although the acceptor properties of these cations in the solid state are greatly diminished by their coordination and screening by anions, yet the monotonic trend is preserved (Fig. 4).

\section{Size matters: the ionic radii within the isoelectronic series}

Alternatively, one might say that going along the isoelectronic series from $\mathrm{Sc}$ (III) to $\mathrm{Mn}$ (VII) the d orbitals should be more and more contracted, with maxima of integrated electron density closer and closer to nucleus. Indeed, inspection of the ionic radii in this series (modified Shannon radii) (Shannon 1976) shows a decreasing trend in both 6- and 4-coordinated series, with the values of 88.5 pm [6-coordinated $\mathrm{Sc}$ (III)], $74.5 \mathrm{pm}$ [6-coordinated $\mathrm{Ti}(\mathrm{IV})], 68 \mathrm{pm}$ [6-coordinated $\mathrm{V}(\mathrm{V})$ ], $58 \mathrm{pm}$ [6-coordinated $\mathrm{Cr}(\mathrm{VI})$ ], with a small increase up to $60 \mathrm{pm}$ [6-coordinated $\mathrm{Mn}(\mathrm{VII})]$, and $56 \mathrm{pm}$ [4-coordinated Ti(IV)], $49.5 \mathrm{pm}$ [4-coordinated $\mathrm{V}(\mathrm{V})$ ], $40 \mathrm{pm}$ [4-coordinated $\mathrm{Cr}(\mathrm{VI})$ ], and $39 \mathrm{pm}$ [4-coordinated $\mathrm{Mn}(\mathrm{VII})$ ] (Fig. 5). This substantial size reduction (by ca. 1/3 regardless of the $\mathrm{CN}$ ) obviously remains in mutual interrelation with diffuseness/compactness of outermost valence orbitals which determine size of the atomic species.

Size and electron-acceptor property of isoelectronic cations are certainly interrelated. The only complication one may encounter in such comparison is seen for very small cations, as exemplified by $\mathrm{Mn}(\mathrm{VII})$ in this series. The fact that its tetrahedral ionic radius is slightly larger than that of $\mathrm{Cr}(\mathrm{VI})$, counterintuitively, comes from the fact that lone pairs on ligands come too close to one another and they exhibit strong Coulomb and Pauli repulsion. But one faces this problem relatively seldom.

\section{Back to MOs: ionicity and covalence}

It is now time to abandon the simple ionic picture which we have used before, and introduce AO mixing (Fig. 6). It is naturally expected that the bonding between TM and O will be polarized towards $\mathrm{O}$; this is indeed the case for species studied here. However, the degree of iconicity is not identical in this series, and-as TM orbitals are closer and closer to those of $\mathrm{O}$ (Fig. 3), covalency increases. Thus, $\mathrm{Sc}-\mathrm{O}$ bonding is most and $\mathrm{Mn}-\mathrm{O}$ one the least ionic in the series, with the covalent contribution obviously behaving in the opposite way. This is certainly reflected in the literature where there is no much discussion of $\mathrm{Sc}(\mathrm{III})-\mathrm{O}$ bonding in terms of MOs (it is assumed they are pretty ionic) while a similar

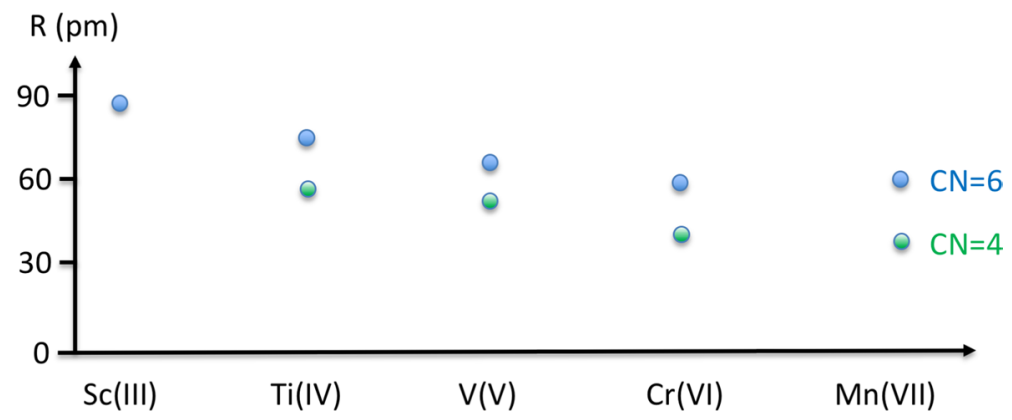

Fig. 5 The trend of ionic radii for isoelectronic series of TM cations for coordination number (CN) of 4 and 6 

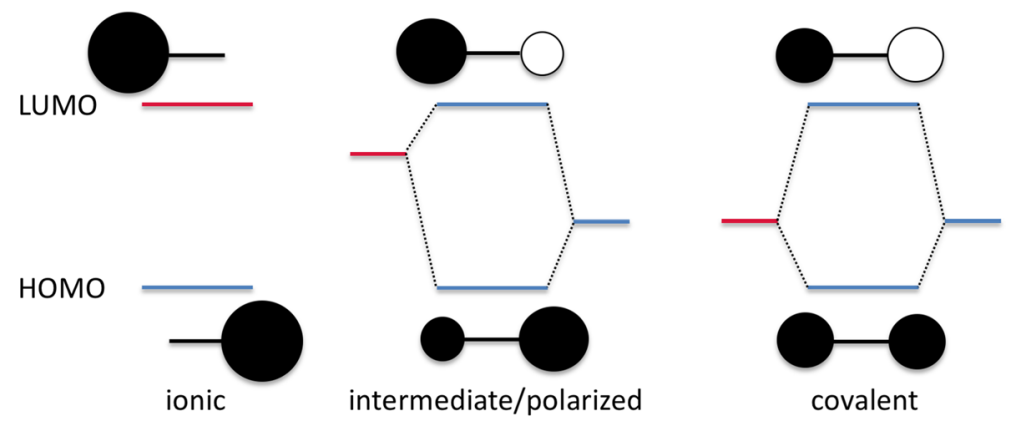

Fig. 6 The bonding and antibonding MOs of a diatomic molecule with only s valence electrons and omitting admixture of other AOs. Left: "ideal" ionic picture, with AOs of constituent atoms infinitely separated from each other in the energy scale. The separation of orbitals is obviously finite in the picture. Middle: an intermediate situation leading to polarized bonding, as e.g. for LiH. Right: "ideal" covalent situation for a homonuclear molecule, such as $\mathrm{H}_{2}$

assumption for $\mathrm{Mn}(\mathrm{VII})-\mathrm{O}$ bonds would be met by brews raising. Both $\sigma$ and $\pi$ components to bonding and its departure from double character are frequently discussed for the $\mathrm{Mn}(\mathrm{VII})-\mathrm{O}$ bonds.

Given that the separation of HOCO and LUCO of $\mathrm{Mn}(\mathrm{VIII})_{2} \mathrm{O}_{7}$ is rather small one may even anticipate the situation of the "ligand field inversion" (Hoffmann et al. 2016), where the occupied orbitals are more centered on the TM, while the unoccupied ones on the nonmetal. Such construct of the holes in nonmetal bands has been discussed in solid state physics (Sawatzky and Green 2016). We will return to this fascinating phenomenon below while discussing the case of $\mathrm{FeO}_{4}$.

\section{Lewis acid/base properties and ternary compositions}

The very same HOCO/LUCO diagram (Fig. 3) helps to understand acid-base properties of the TM oxides considered. The MO which changes most its energy is LUCO. Since this is an acceptor orbital, it is expected that the acidic properties of the TM oxides will generally increase from left to right within this part of Period IV. Indeed, complex ternary salts (Fig. 7) are readily formed when the TM oxides are reacted with a colorless Lewis basic alkali or alkali earth metal oxide, e.g.:

$$
1 / 2 \mathrm{Mn}_{2} \mathrm{O}_{7}+1 / 2 \mathrm{~K}_{2} \mathrm{O} \rightarrow \mathrm{KMnO}_{4},
$$

or

$$
\mathrm{CrO}_{3}+1 / 2 \mathrm{~K}_{2} \mathrm{O} \rightarrow 1 / 2 \mathrm{~K}_{2} \mathrm{Cr}_{2} \mathrm{O}_{7}
$$

and

$$
1 / 2 \mathrm{~K}_{2} \mathrm{Cr}_{2} \mathrm{O}_{7}+1 / 2 \mathrm{~K}_{2} \mathrm{O} \rightarrow \mathrm{K}_{2} \mathrm{CrO}_{4}
$$

The formal oxidations states of the TM do not change during these reactions.

The heat effect (reaction enthalpy) of such reactions might be quantified based on the tables of thermodynamic data (some data being unavailable) (https://webbook.nist.gov/ chemistry/; 2008). For example, the standard enthalpy of reaction with $\mathrm{K}_{2} \mathrm{O}$ per one mole 

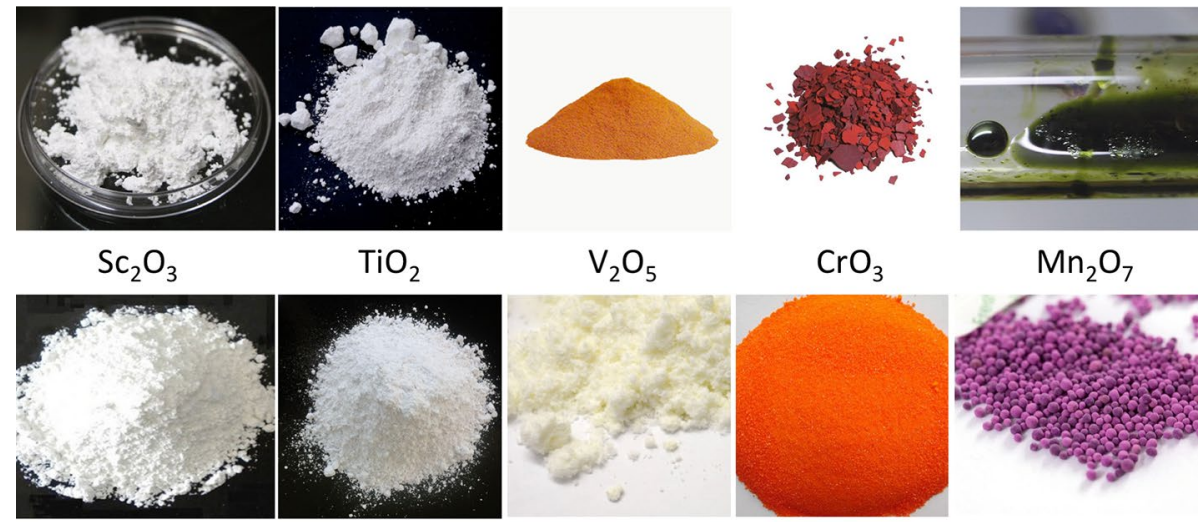

$\mathrm{TiO}_{2}$

$\mathrm{V}_{2} \mathrm{O}_{5}$

$\mathrm{CrO}_{3}$

$\mathrm{Mn}_{2} \mathrm{O}_{7}$
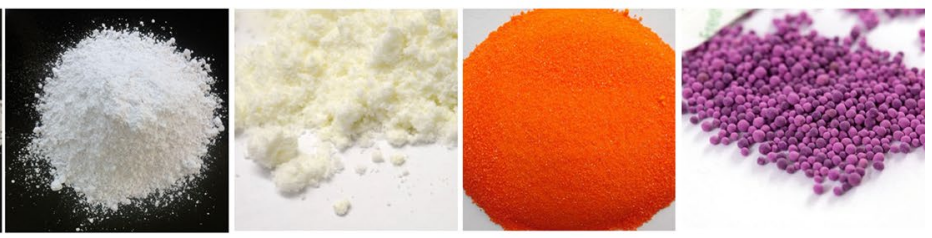

$\mathrm{KScO}_{2}$

$\mathrm{BaTiO}_{3}$

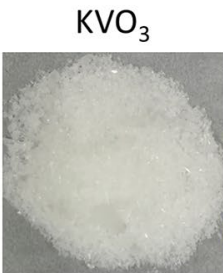

$\mathrm{Na}_{3} \mathrm{VO}_{4}$

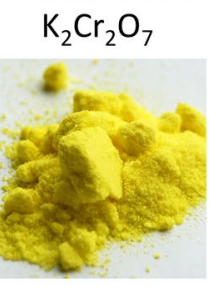

$\mathrm{K}_{2} \mathrm{CrO}_{4}$

$\mathrm{KMnO}_{4}$

Fig. 7 Photographs of the series of five TM oxides considered in this study together with their corresponding salts obtained by addition of colorless alkali or alkali metal oxide base. For $\mathrm{V}$ and $\mathrm{Cr}$ addition is progressive resulting in meta- and orthovanadates, as well as dichromates and chromates. The violet color of $\mathrm{KMnO}_{4}$ is so intense that its crystals appear as nearly black; therefore, alumina balls impregnated with $\mathrm{KMnO}_{4}$ have been showed instead

of TM oxide is ca. $200 \mathrm{~kJ} \mathrm{~mol}^{-1}$ for $\mathrm{V}_{2} \mathrm{O}_{5}$; regretfully, there is no enough data to establish the clear link for the considered series. Nevertheless, the claimed trend of the increasing Lewis acidity seems to be natural; consider the corresponding Brønsted acids: $\mathrm{HScO}_{3}$, $\mathrm{H}_{2} \mathrm{TiO}_{3}, \mathrm{HVO}_{3}, \mathrm{H}_{2} \mathrm{CrO}_{4}$, and $\mathrm{HMnO}_{4}$. While the latter two-albeit unstable-are considered to be strong in aqueous solutions, the first two in the list are not discussed in the literature, their compositions corresponding to oxide-hydroxide rather than true acid.

What is the effect of the addition of a colorless oxide base to the TM oxides on color of the resulting ternary system? Let us turn again to the color wheel. The effects are clearly the strongest for $\mathrm{V}(\mathrm{V}), \mathrm{Cr}(\mathrm{VI})$ and $\mathrm{Mn}(\mathrm{VII})$. Orange color of $\mathrm{V}_{2} \mathrm{O}_{5}$ (absorption in blue) now changes to faint yellow (tail of absorption in violet region) for $\mathrm{KVO}_{3}$ and finally to colorless for $\mathrm{Na}_{3} \mathrm{VO}_{4}$ (absorption in NUV). Similarly, red color of $\mathrm{CrO}_{3}$ (absorption in green) changes to orange (absorption in blue) for $\mathrm{K}_{2} \mathrm{Cr}_{2} \mathrm{O}_{7}$ and then yellow (absorption in violet) for $\mathrm{K}_{2} \mathrm{CrO}_{4}$. Last but not the least, green color of $\mathrm{Mn}_{2} \mathrm{O}_{7}$ (absorption in red) changes dramatically to violet one (absorption in yellow) for $\mathrm{KMnO}_{4}$. Without any doubt, all these changes (blue shift also known as hipsochromic effect) testify to the broadening of the optical (and hence also the fundamental) band gap for these systems upon reaction with a Lewis base.

The discussed changes may now be reformulated using MO picture; here, an electron hungry TM-based LOCO interacts with easily available electronic density from additional basic oxide and partially fulfills its need for electronic density coming from ligands. The 
average number of oxide ligands per TM center increases. Consequently, energy of LOCO becomes less negative and this orbital decreases its TM character, and increases the nonmetal one. The ionicity of TM-O bonds increases in the process and the band gap opens (Fig. 8).

Very similar simplistic considerations may be conducted regarding basicity of the TM oxide series; however, this needs an extra stage of the perturbation theory, since before we have decided to keep the energy of nonmetal levels constant, for the sake of simplicity. In fact, as covalence of the TM-O bonds increases, the lone pair donating ability of oxide anions tends to decrease. But it may increase upon demand when a ternary salt with a rather ionic alkali or alkali earth oxide is formed.

\section{Thermodynamic and thermal stability; kinetic persistence}

It is now time to consider thermodynamic and thermal stability of the TM oxide series. The potential instability in these systems originates from transfer of electrons between $\mathrm{HOCO}$ and LUCO, which leads to reduction of the oxidation state of a metal and evolution of $\mathrm{O}_{2}$. If the metal atom center within the considered isoelectronic series becomes sufficiently positive, its valence d levels lower their energy, a point may be reached where the oxide ligands, central to our normal oxidation state count, are themselves oxidized. The formal $\mathrm{O}^{--}$or even $\mathrm{O}$ atom (neutral), will dimerize, to give peroxide or $\mathrm{O}_{2}$, respectively, with $\mathrm{OO}$ bonds. The formation and coordination of $\mathrm{O}_{2}$ or superoxide or peroxide is a possibility that must always be faced in high oxidation state oxides. However, at some finite temperature
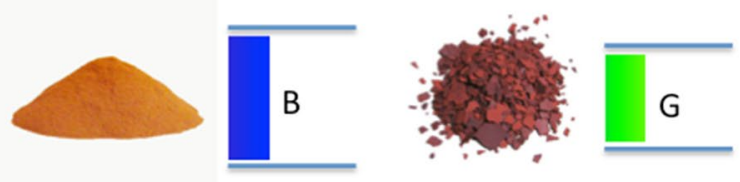

$\mathrm{V}_{2} \mathrm{O}_{5}$
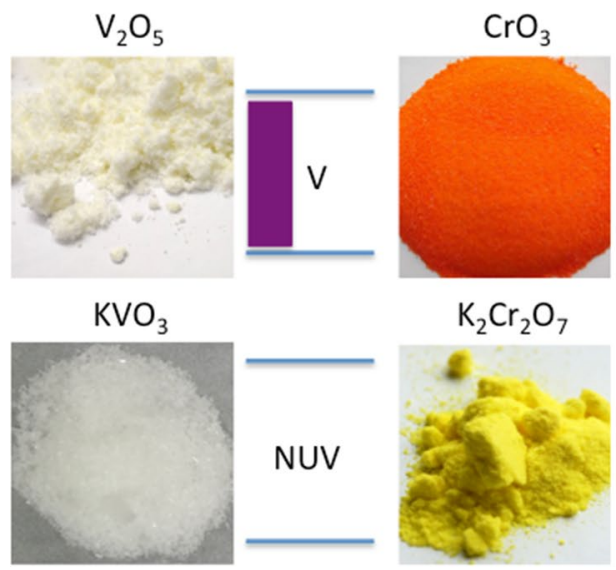

$\mathrm{Na}_{3} \mathrm{VO}_{4}$

$$
\mathrm{K}_{2} \mathrm{Cr}_{2} \mathrm{O}_{7}
$$
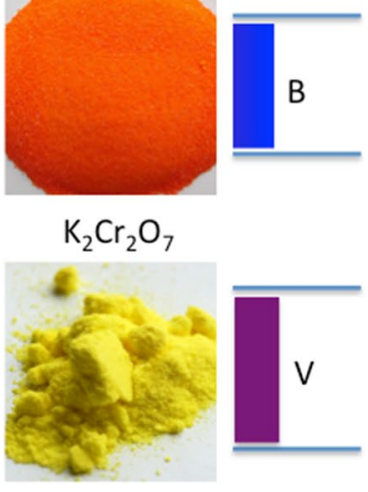

$$
\mathrm{K}_{2} \mathrm{CrO}_{4}
$$

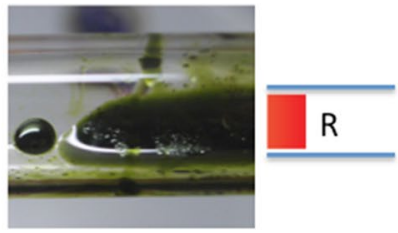

$\mathrm{Mn}_{2} \mathrm{O}_{7}$

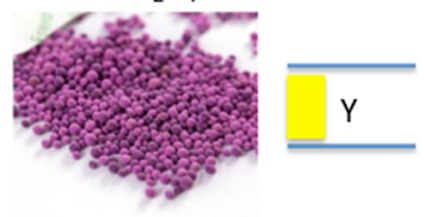

$\mathrm{KMnO}_{4}$

Fig. 8 Schematic band gap opening during Lewis acid-Lewis base reactions (Eqs. 1-3) as exemplified by V, $\mathrm{Cr}$ and $\mathrm{Mn}$ species. Progressive addition of Lewis bases is from the top to the bottom 
the entropy factor from gaseous product $\left(\mathrm{O}_{2}\right)$ would prevail the enthalpic one, and thermal decomposition would commence. Let us then analyze thermal stability of our oxide series.

Thus, $\mathrm{Sc}_{2} \mathrm{O}_{3}$ is immensely stable; one may actually melt it (at $2485{ }^{\circ} \mathrm{C}$ ) without decomposition. $\mathrm{TiO}_{2}$ may also be melted (at $1843{ }^{\circ} \mathrm{C}$ ); however, as it is known from the early days of XPS spectroscopy, surface of titania easily loses $\mathrm{O}$ atoms in ultra-high vacuum, and the surface is O-deficient (Pan et al. 2013). The case of $\mathrm{V}_{2} \mathrm{O}_{5}$ is even more interesting: the melting point is $690{ }^{\circ} \mathrm{C}$ but the compound cannot be boiled without decomposition and it loses some $\mathrm{O}_{2}$ already at melting. Actually, when placed in the stream of $\mathrm{O}_{2}$ it undergoes a dynamic $\mathrm{O}$ exchange; this feature has been utilized for certain oxygenation reactions (such as synthesis of $\mathrm{SO}_{3}$ from $\mathrm{SO}_{2}$ ) carried out in the presence of $\mathrm{V}_{2} \mathrm{O}_{5}$ as a catalyst (https:// en.wikipedia.org/wiki/Vanadium(V)_oxide). Blood red $\mathrm{CrO}_{3}$ is not stable without protective $\mathrm{O}_{2}$ atmosphere; in vacuum or a stream of inert gas its surface immediately darkens and covers with dark green $\mathrm{Cr}_{2} \mathrm{O}_{3}$. Finally, $\mathrm{Mn}_{2} \mathrm{O}_{7}$ is so unstable, that at room temperature there exists a risk of its violent decomposition with $\mathrm{O}_{2}$ release (https://en.wikipedia.org/ wiki/Manganese_heptoxide).

There is a clear trend of thermodynamic and thermal stability in this series. One may also notice that the band gap opening (discussed above) upon formation of ternary derivatives leads to improvement of stability. Chromates and permanganates need to be heated in order to liberate $\mathrm{O}_{2}$ from them.

\section{Reactivity and the maximum hardness principle}

The fundamental i.e. HOCO/LUCO gap has yet another important for the the course of chemical reactions involving said TM oxides. During chemical reactions local symmetry must be broken and HOCO must admix some portion of LUCO to activate the system (transition state); the narrower the band gap, the easier it is, hence the gap determines kinetics of the reactions. According to the grand theorem by Pearson, chemical systems protect the band gap (Pearson 1993) by keeping it as high as possible for stable configurations of nuclei (minima) (Grochala 2017a, b). Pearson's hardness, $\eta$, is in fact nicely approximated by half of the fundamental band gap for both molecules (HOMO/LUMO) and solids (HOCO/LUCO).

No wonder the human-made catalysts (oxides, sulfides) are so often heavily colored; Nature might have used a (nearly band gapless) $\mathrm{FeS}_{2}$ for important biochemical reactions. Our world is made of many thermodynamic sinks, which are colorless $\left(\mathrm{SiO}_{2}, \mathrm{CO}_{2}, \mathrm{H}_{2} \mathrm{O}\right.$, $\mathrm{N}_{2}$, Ar, etc.). And yet, life has found its ways to begin, to continue, and to be immensely colorful in each sense of the world.

\section{Redox properties}

The familiar HOCO/LUCO diagram (Fig. 3) may be used to analyze redox reactivity of the TM oxides. It is more instructive to do this by analyzing electron-acceptor (reduction) properties, since d orbitals are empty and waiting for electrons. Obviously, the orbitals involved in the redox reactions (transfer of, say, one electron) are the same LUCO orbitals which we have previously involved in considerations of the Lewis acidic properties (accepting of an electron pair). While it would be nice to analyze the entire series of standard redox potentials (in, say, acidic aqueous environment), yet the variety of oxidation states adopted by these elements does not permit us to do this consistently. Nevertheless, it comes with no surprise at all that $\mathrm{Sc}$ (III) oxide is not considered to be 
a good oxidizing agent; nor is $\mathrm{TiO}_{2}$. On the other hand, as we have seen, $\mathrm{V}_{2} \mathrm{O}_{5}$ is capable of doing some oxidation reactions while $\mathrm{CrO}_{3}$ and $\mathrm{KMnO}_{4}$ are used for exhausting oxidations in organic chemistry (and for rigorous glassware cleaning). $\mathrm{Mn}_{2} \mathrm{O}_{7}$ is so powerful and reactive oxidizing agent that delivers sparks in contact with $\mathrm{EtOH}$ in a famous experiment (https://www.thoughtco.com/test-tube-thunderstorm-demonstration-604255).

It is natural to expect the relationships between energies of frontier orbitals, the redox potentials, and optical band gap. Some applied this approach successfully for years while trying to rationalize the observed trends (Lever 1990; Dodsworth and Lever 1986).

\section{Working summary}

The relationship between the observed color and several key features or common physicochemical descriptors of chemical systems discussed above, is summarized in Fig. 9. This is a central figure of this paper, reflecting the qualitative thinking about different properties under one roof. Once embedded in a student's mind it should help him or her to use it in practice by proposing a solution of his/her research problem using
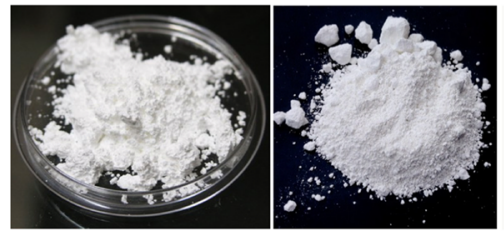

$\mathrm{Sc}_{2} \mathrm{O}_{3}$

$\mathrm{TiO}_{2}$
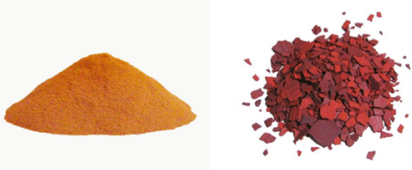

$\mathrm{CrO}_{3}$

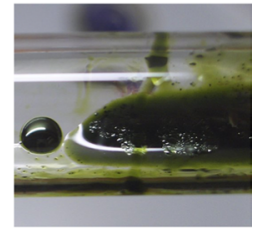

$\mathrm{V}_{2} \mathrm{O}_{5}$

$\mathrm{Mn}_{2} \mathrm{O}_{7}$

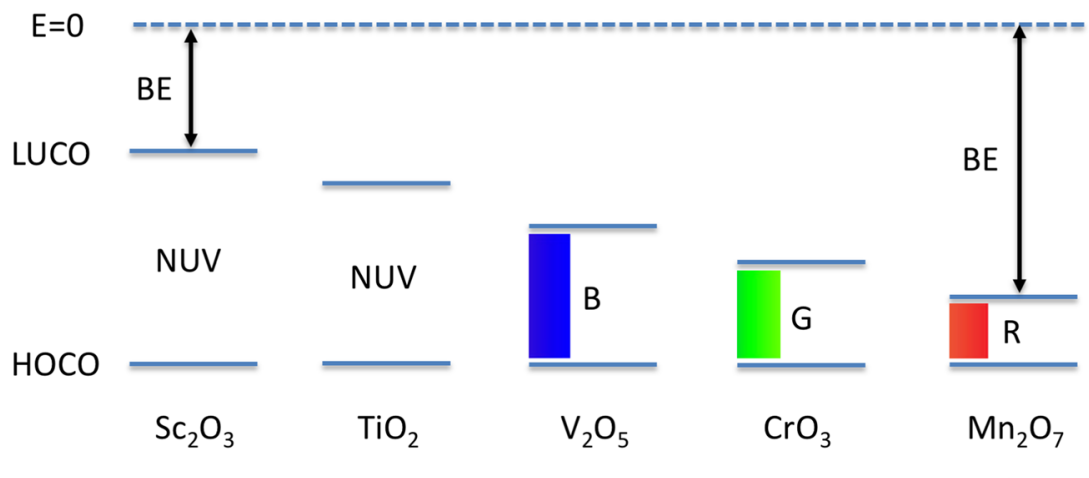

M-O bond covalence, Lewis acidity, oxidizing character, thermal and thermodynamic instability, electronic softness, kinetics of reactions

$\mathrm{M}-\mathrm{O}$ bond ionicity, Lewis basicity, $\mathrm{CT}$ and optical gap, $\mathrm{M}$ ionic radius, $\mathrm{M}$ preferred $\mathrm{CN}$, thermal and thermodynamic stability, Pearson hardness

Fig. 9 Summary of qualitative relationships between color of TM oxides and important physicochemical properties or descriptors 
isoelectronic substitutions. The strength of this approach is in monotonic change of key features across the series, so each feature may be deliberately manipulated.

\section{Into the unknown: $\mathrm{Fe}(\mathrm{VIII}) \mathrm{O}_{4}$}

Having established all monotonic qualitative trends of properties in the series of TM oxides, we may now use this knowledge (contributing already to what is called intuition) for understanding the last member of the series, $\mathrm{FeO}_{4}$. As already said, this system has not yet been prepared although its heavier homologues, yellow $\mathrm{RuO}_{4}$ and faintly yellow $\mathrm{OsO}_{4}$, are well known and used in organic chemistry as mild yet selective oxidizers. Extending the already established trends to $\mathrm{FeO}_{4}$ is straightforward in nearly all cases. This elusive compound should exhibit the following properties:

- Have very narrow optical and fundamental gaps, likely falling in the NIR region; due to many other higher energy excitations it would likely be black;

- Its MOs should exhibit substantial mixture of metal and oxygen AOs; bonds should be covalent; the occurrence of the inverse ligand field is likely;

- The compound should be immensely unstable thermally and thermodynamically;

- It would be an extremely reactive compound and a strong oxidizer;

- Its very poor Lewis acidity is the only property which likely would not follow the monotonic trend established before; this is due to very small expected size of Fe(VIII) cation, with no room for extra ligands. Huge steric repulsion of lone pairs on $\mathrm{O}$ atoms is expected for $\mathrm{FeO}_{4}$.

\section{Validation: theoretical results for $\mathrm{Fe}(\mathrm{VIII}) \mathrm{O}_{4}$}

Fortunately, we do not need to wait for the preparation of $\mathrm{FeO}_{4}$ because very high-level quantum mechanical calculations have already been performed for this molecule (Huang et al. 2016). The outcome of the calculations is as follows:

- The mixing of the $\mathrm{Fe}(\mathrm{d})$ and $\mathrm{O}(\mathrm{p})$ orbitals is so large that a single determinant based methods spectacularly fail in consistent description of the properties for this molecule;

- The minimum corresponding to $\mathrm{Fe}(\mathrm{VIII}) \mathrm{O}_{4}$ formulation is unstable thermodynamically by ca. $0.5 \mathrm{eV}$ with respect to the ground state (peroxo-dioxide complex of $\mathrm{Fe}(\mathrm{VI})$ ); ease of thermal decomposition via auto-redox reaction may be anticipated, supporting the surmise of the inverse ligand field.

Hence, some of the calculated key properties of the molecule of interest agree nicely with the predictions based on qualitative thinking. Others must await experimental confirmation.

\section{Excursion towards heavier elements and higher periods}

Having studied TM oxides for light TMs, it is time to look at their heavier analogues. Let us watch their colors. It is clear from Fig. 10 that their Period V and VI analogues have much fainter colors, if any; colorless and yellowish compounds predominate. This obviously may be linked retrospectively with all other properties discussed above in the spirit of similar 


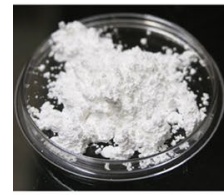

$\mathrm{Sc}_{2} \mathrm{O}_{3}$

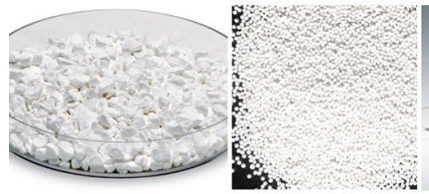

$\mathrm{Y}_{2} \mathrm{O}_{3}$

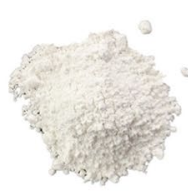

$\mathrm{La}_{2} \mathrm{O}_{3}$

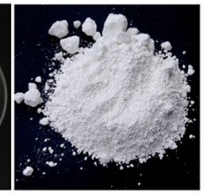

$\mathrm{TiO}_{2}$

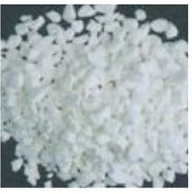

$\mathrm{HfO}_{2}$

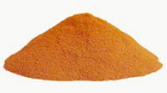

$\mathrm{V}_{2} \mathrm{O}_{5}$

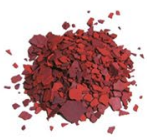

$\mathrm{CrO}_{3}$
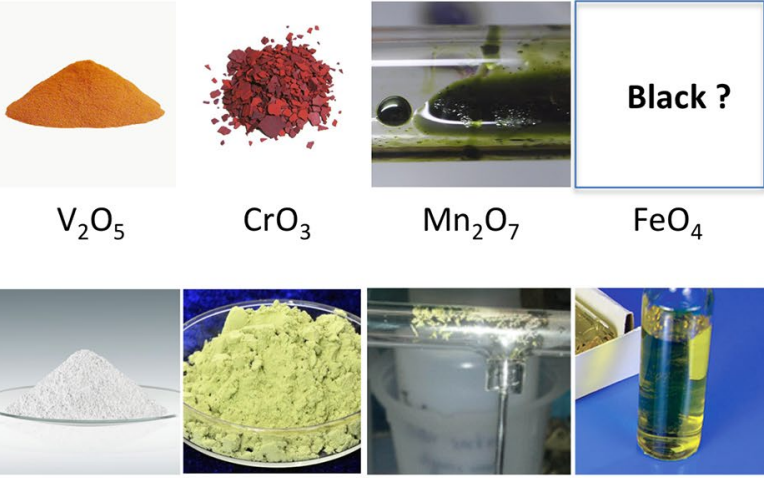

$\mathrm{Nb}_{2} \mathrm{O}_{5}$

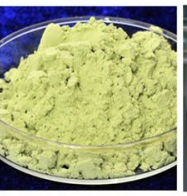

$\mathrm{MoO}_{3}$
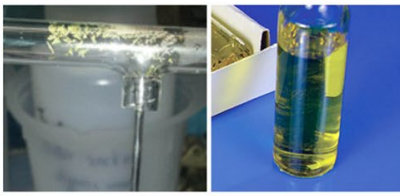

$\mathrm{Tc}_{2} \mathrm{O}_{7}$

$\mathrm{RuO}_{4}$

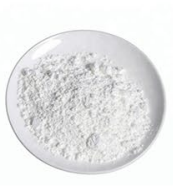

$\mathrm{Ta}_{2} \mathrm{O}_{5}$

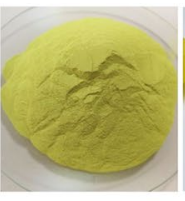

$\mathrm{WO}_{3}$

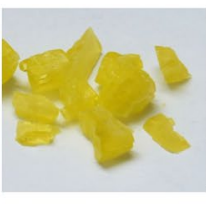

$\mathrm{Re}_{2} \mathrm{O}_{7}$

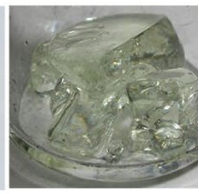

$\mathrm{OsO}_{4}$

Fig. 10 Photographs of the series of TM oxides based on TMs from periods IV, V and VI. $\mathrm{RuO}_{4}$ is shown as solution but the color of its crystals is very similar

qualitative considerations, and monotonic trends. While lack of color in the visible range carries no much information yet the inspection of the UV spectra of these compounds and or studies of their electronic conductivity using impedance spectroscopy would certainly permit establishing a very similar set of trends as that already discussed. For example, fundamental band gap of yttria is estimated from experiment at about $5.5 \mathrm{eV}$, that of zirconia may be smaller for certain polymorphic forms, around $5 \mathrm{eV}$, the value for niobia is $3.4 \mathrm{eV}$, and that of $\mathrm{MoO}_{3}$ is similar. It should be remembered that relativistic effects may bend the nice trends observed so far, especially when going down to Period VI of the Table. This is why lack of monotonicity is seen across Period VI as far as color is concerned, and nearly colorless $\mathrm{OsO}_{4}$ follows the yellowish $\mathrm{Re}_{2} \mathrm{O}_{7}$. The scalar relativistic effects are largely responsible for strong destabilization of $\mathrm{d}$ orbitals of Os (as compared to $\mathrm{Ru}$ ) and thus larger opening of the fundamental band gap (Pyykkö 2012). But bending of a general trend (Fig. 9) may easily be explained to a student willing to go beyond general course of quantum mechanics understand some unique features of heavy and super-heavy elements. Importantly, scalar corrections may be viewed within the MO theory merely as affecting the orbital energies and compactness/diffuseness of atomic orbital functions, hence the MO language may be preserved.

\section{Other examples of application of qualitative thinking}

Monotonic trends are of immediate practical use in chemistry, because they clearly indicate the direction in which chemical modifications should go to minimize or maximize a 
given physicochemical property (extrapolation). In some instances, one must balance a certain parameter to obtain a desired value of a property, which falls in between those for the already known systems (interpolation). This author has been involved in some problems, where he applied qualitative thinking with an immediate outcome. Among those were:

- The problem of adjusting of the temperature of thermal decomposition for metal hydrides to provide $\mathrm{H}_{2}$ gas of arbitrarily set temperature to the fuel cells; (Grochala and Edwards 2004)

- The problem of lack of reactivity of the two lightest noble gases, He and Ne, which was partly solved; (Grochala 2009; Grochala 2012; Szarek and Grochala 2015) this research clearly pointed out to the placement of He in the Group 2 of the Periodic Table to satisfy all important monotonic relationships as expected for same group elements; (Grochala 2018)

- The problem of finding of an analog of copper(II) oxides which become superconducting upon doping; the inspection of literature clearly pointed towards $\mathrm{Ag}$ (II) fluorides (Grochala and Hoffmann 2001), as they and especially their hole-doped Ag(III) analogs are thermally unstable and evolve $\mathrm{F}_{2}$ gas with ease; (Lucier et al. 1998) this also explains their powerful electron acceptor properties (Lucier et al. 1995), as well as unprecedented covalence of $\mathrm{Ag}$ (II)-F bonding (Grochala 2018), which has been confirmed in experiment (Grochala et al. 2003). Ultimately, the facile $\operatorname{Ag}(d) / F(p)$ mixing (covalence) leads to strong magnetic superexchange, which again has been first predicted by theory (Jaroń and Grochala 2008; Kurzydłowski and Grochala 2017), and later confirmed experimentally (Kurzydłowski et al. 2013; Gawraczyński et al. 2019; Kurzydłowski and Grochala 2017; Gawraczyński et al. 2019).

- Similarly, it was black color of a solid residue observed during reaction between $\mathrm{AgF}_{2}$ and $\mathrm{H}_{2} \mathrm{SO}_{4}$ (Malinowski et al. 2008) which has led us to preparation of the metastable $\mathrm{AgSO}_{4}$ (Malinowski et al. 2010), with all of its interesting chemistry which followed (Malinowski et al. 2011; Budniak et al. 2017).

While chemical systems come with great diversity of structures and properties, and may be in a sense unique, one always attempts to see some similarities to the known systems. In particular, one attempts to compare the know system to isoelectronic ones, be them in the same Period or Group of the Periodic Chart. Here, we have selected one particular family of compounds, i.e. oxides of TMs at the highest achievable oxidation state of a metal, for illustration of the guiding principles. However, one may choose another isoelectronic series. While performing comparative analyses, one often utilizes the great power of qualitative thinking for rationalizing the observed properties of the newly prepared system. This in turn offers a unique possibility to predict properties of as yet unknown species from the same series, without performing any quantum mechanical calculations. Yet another powerful use of this simple method-which may be supported by quantum mechanical calculations-consists of predicting of the properties of as yet unknown system, and identifying possible problems connected with its synthesis. Chemists use qualitative thinking a lot in their research and it would be delightful if such approach was taught to students more broadly, even in specialized courses at the late stages of undergraduate education. And although the very perception of color is subjective (Poncini and Wimmer 1987; Williams et al. 2009), it is advisable to use qualitative thinking before we, humans, become useless in the forthcoming era of machine learning (Kulik 2020; Jia et al. 2019; Coley et al. 2019). 
Acknowledgements The author is grateful to Roald Hoffmann for introducing him to qualitative thinking, and for suggesting improvements to this manuscript. The examples of silver(II) and silver(III) chemistry resulting from this approach were possible due to funding from the Polish National Science Center, NCN, within the project Maestro (2017/26/A/ST5/00570). WG would like to thank the younger members of his research group which patiently support his frequent obsessive questions about the color of new compounds prepared by them (with emphasis on black).

Open Access This article is licensed under a Creative Commons Attribution 4.0 International License, which permits use, sharing, adaptation, distribution and reproduction in any medium or format, as long as you give appropriate credit to the original author(s) and the source, provide a link to the Creative Commons licence, and indicate if changes were made. The images or other third party material in this article are included in the article's Creative Commons licence, unless indicated otherwise in a credit line to the material. If material is not included in the article's Creative Commons licence and your intended use is not permitted by statutory regulation or exceeds the permitted use, you will need to obtain permission directly from the copyright holder. To view a copy of this licence, visit http://creativecommons.org/licenses/by/4.0/.

\section{References}

Budniak, A., Leszczyński, P.J., Masny, M., Prezelj, K., Grzeszkiewicz, M., Gilewski, T.E., Gawraczyński, J., Dobrzycki, Ł., Cyrański, M.K., Koźmiński, W., Mazej, Z., Fijałkowski, K.J., Grochala, W.: Reconnaissance of reactivity of $\mathrm{Ag}(\mathrm{II}) \mathrm{SO}_{4}$ one-electron oxidizer towards naphthalene derivatives. New J. Chem. 41(19), 10742-10749 (2017)

Chemistry webbook.: https://webbook.nist.gov/chemistry/. Accessed Mar 2020

Chromium trioxide.: https://en.wikipedia.org/wiki/Chromium_trioxide. Accessed Mar 2020

Coley, C.W., Jin, W., Rogers, L., Jamison, T.F., Jaakkola, T.S., Green, W.H., Barzilay, R., Jensen, K.F.: A graph-convolutional neural network model for the prediction of chemical reactivity. Chem. Sci. 10(2), 370-377 (2019)

Dodsworth, E.S., Lever, A.B.P.: Correlations between electrochemical potentials and optical charge transfer energies in ruthenium bipyridine derivatives. Chem. Phys. Lett. 124(2), 152-158 (1986)

Gawraczyński, J., Mazej, Z., Blundell, S.J., Grochala, W.: AgFBF 4 : possibly the most strongly coupled and nearly one-dimensional quantum antiferromagnet. Superstripes 2019. In: The International Conference: Quantum physics in Complex Matter: Superconductivity, Magnetism and Ferroelectricity (2019)

Gawraczyński, J., Kurzydłowski, D., Ewings, R., Bandaru, S., Gadomski, W., Mazej, Z., Ruani, G., Bergenti, I., Jaroń, T., Ozarowski, A., Hill, S., Leszczyński, P.J., Tokár, K., Derzsi, M., Barone, P., Wohlfeld, K., Lorenzana, J., Grochala, W.: Silver route to cuprate analogs. Proc. Natl. Acad. Sci. USA 116(5), 1495-1500 (2019)

Grochala, W.: On chemical bonding between helium and oxygen. Pol. J. Chem. 83(1), 87-122 (2009)

Grochala, W.: Metastable He-O bond inside a ferroelectric molecular cavity: $(\mathrm{HeO})(\mathrm{LiF})_{2}$. Phys. Chem. Chem. Phys. 14, 14860-14868 (2012)

Grochala, W.: The Maximum Hardness Principle revisited and applied to atoms and molecules. Phys. Chem. Chem. Phys. 19(46), 30964-30983 (2017a)

Grochala, W.: The Maximum Hardness Principle revisited and applied to solids (Part 2). Phys. Chem. Chem. Phys. 19(46), 30984-31006 (2017b)

Grochala, W.: On the position of helium and neon in the Periodic Table of Elements. Found. Chem. 20(3), 191-207 (2018)

Grochala, W., Edwards, P.P.: Hydrides of the chemical elements for the storage and production of hydrogen. Chem. Rev. 104(3), 1283-1315 (2004)

Grochala, W., Hoffmann, R.: Real and hypothetical intermediate-valence fluoride $\mathrm{Ag}^{\mathrm{II}} / \mathrm{Ag}^{\mathrm{III}}$ and $\mathrm{Ag}^{\mathrm{II}} / \mathrm{Ag}^{\mathrm{I}}$ systems as potential superconductors. Angew. Chem. Int. Ed. Engl. 40(15), 2742-2781 (2001)

Grochala, W., Egdell, R.G., Edwards, P.P., Mazej, Z., Žemva, B.: On the covalency of the Ag-F bonds in compounds of $\mathrm{Ag}^{\mathrm{I}}, \mathrm{Ag}^{\mathrm{II}}$ and $\mathrm{Ag}^{\mathrm{III}}$. ChemPhysChem 4(9), 997-1001 (2003)

Hoffmann, R.: Qualitative thinking in the age of modern computational chemistry-or what Lionel Salem knows. J Mol Struct (Theochem) 424(1-2), 1-6 (1998)

Hoffmann, R., Alvarez, S., Mealli, C., Falceto, A., Cahill, T.J., Zeng, T., Manca, G.: From widely accepted concepts in coordination chemistry to inverted ligand fields. Chem. Rev. 116(14), 8173-8192 (2016) 
Huang, W., Xing, D.-H., Lu, J.-B., Long, B., Schwarz, W.H.E., Li, J.: How much can density functional approximations (DFA) fail? The extreme case of the $\mathrm{FeO}_{4}$ species. J. Chem. Theory Comput. 12(4), 1525-1533 (2016)

Jaroń, T., Grochala, W.: Prediction of giant antiferromagnetic coupling in exotic fluorides of $\mathrm{Ag}^{\mathrm{II}}$. Phys. Status Solidi Rapid Res. Lett. 2(2), 71-73 (2008)

Jia, X., Lynch, A., Huang, Y., Danielson, M., Lang'at, I., Milder, A., Ruby, A.E., Wang, H., Friedler, S.A., Norquist, A.J., Schrier, J.: Anthropogenic biases in chemical reaction data hinder exploratory inorganic synthesis. Nature 573(7773), 251-255 (2019)

Knovel Critical Tables, 2nd edn. Knovel, Norwich (2008)

Kulik, H.J.: Making machine learning a useful tool in the accelerated discovery of transition metal complexes. Wiley Interdiscip. Rev. Comput. Mol. Sci. 10(1), e1439 (2020)

Kurzydłowski, D., Grochala, W.: Prediction of extremely strong antiferromagnetic superexchange in silver(II) fluorides: challenging the oxocuprates(II). Angew. Chem. Int. Ed. Engl. 56(34), 10114-10117 (2017)

Kurzydłowski, D., Mazej, Z., Jagličić, Z., Filinchuk, Y., Grochala, W.: Structural transition and unusually strong $1 \mathrm{D}$ antiferromagnetic superexchange coupling in perovskite $\mathrm{KAgF}_{3}$. Chem. Commun. 49(56), 6262-6264 (2013)

Lever, A.B.P.: Electrochemical parametrization of metal complex redox potentials, using the ruthenium(III)/ ruthenium(II) couple to generate a ligand electrochemical series. Inorg. Chem. 29(6), 1271-1285 (1990)

Lucier, G.M., Shen, C., Casteel, W.J., Chacón, L., Bartlett, N.: Some chemistry of high oxidation state transition metal fluorides in anhydrous HF. J. Fluor. Chem. 72(2), 157-163 (1995)

Lucier, G.M., Whalen, J.M., Bartlett, N.: High yield room temperature syntheses of $\mathrm{KAgF}_{4}$ and $\mathrm{AgF}_{3}$ and the preparation and unit cell of $\mathrm{LiAgF}_{4}$. J. Fluor. Chem. 89(1), 101-104 (1998)

Malinowski, P., Mazej, Z., Grochala, W.: Probing reactivity of the potent $\mathrm{AgF}_{2}$ oxidizer Part 1: organic compounds. Collect. Czech. Chem. Commun. 73(12), 1729-1746 (2008)

Malinowski, P., Derzsi, M., Gaweł, B., Łasocha, W., Jagličić, Z., Mazej, Z., Grochala, W.: Ag ${ }^{\mathrm{II}} \mathrm{SO}_{4}$ : genuine sulfate of divalent silver with anomalously strong 1D antiferromagnetic interactions. Angew. Chem. Int. Ed. Engl. 49(9), 1683-1686 (2010)

Malinowski, P., Budzianowski, A., Leszczyński, P., Gaweł, B., Grochala, W.: Unusual thermal decomposition of $\mathrm{Ag}(\mathrm{II}) \mathrm{SO}_{4}$ yielding $\mathrm{Ag}(\mathrm{I})_{2} \mathrm{~S}_{2} \mathrm{O}_{7}$ : bending the Hammond's rule. Eur. J. Chem. 17(38), 1052410527 (2011)

Manganese heptoxide.: https://en.wikipedia.org/wiki/Manganese_heptoxide. Accessed Mar 2020

Pan, X., Yang, M.-Q., Fu, X., Zhang, N., Xu, Y.-J.: Defective $\mathrm{TiO}_{2}$ with oxygen vacancies: synthesis, properties and photocatalytic applications. Nanoscale 9, 3601-3614 (2013). (See this paper and references therein)

Pearson, R.G.: The principle of maximum hardness. Acc. Chem. Res. 26(5), 250-255 (1993)

Poncini, L., Wimmer, F.L.: Color classification of coordination compounds. J. Chem. Educ. 64(12), 10011002 (1987)

Pyykkö, P.: Relativistic effects in chemistry: more common than you thought. Annu. Rev. Phys. Chem. 63, 45-64 (2012)

Sawatzky, G., Green, R.: The explicit role of anion states in high-valence metal oxides. In: Pavarini, E., Koch, E., van den Brink, J., Sawatzky, G. (eds.) Quantum materials: experiments and theory. Modeling and simulation, vol. 6. Forschungszentrum, Julich (2016)

Shannon, R.D.: Revised effective ionic radii and systematic studies of interatomic distances in halides and chalcogenides. Acta Crystallogr. A A32, 751-767 (1976)

Szarek, P., Grochala, W.: Noble gas monoxides stabilized in dipolar cavity: a theoretical study. J. Phys. Chem. A 119(11), 2483-2489 (2015)

Test Tube Thunderstorm Demonstration.: https://www.thoughtco.com/test-tube-thunderstorm-demonstrat ion-604255. Accessed Mar 2020

Titanium dioxide.: https://en.wikipedia.org/wiki/Titanium_dioxide. Accessed Mar 2020

Vanadium(V) oxide.: https://en.wikipedia.org/wiki/Vanadium(V)_oxide. Accessed Mar 2020

Williams, D.L., Flaherty, T.J., Alnasleh, B.K.: Beyond $\lambda_{\max }$ part 2: predicting molecular color. J. Chem. Educ. 86(3), 333-339 (2009)

Publisher's Note Springer Nature remains neutral with regard to jurisdictional claims in published maps and institutional affiliations. 